South African Journal of Geomatics, Vol. 5. No. 3, November 2016

\title{
Accuracy comparison of Pléiades satellite ortho-images using GPS device based GCPs against TerraSAR-X-based GCPs
}

\author{
Ivan Henrico ${ }^{1}$, Ludwig Combrinck ${ }^{1,2}$ and Corné Eloff ${ }^{3}$ \\ ${ }^{1}$ Department of Geography, Geoinformatics and Meteorology, University of Pretoria, South Africa, \\ ivan.henrico@sita.co.za \\ ${ }^{2}$ Hartebeesthoek Radio Astronomy Observatory \\ ${ }^{3}$ Airbus Defence and Space, Geo-Intelligence
}

\section{http://dx.doi.org/10.4314/sajg.v5i3.7}

\begin{abstract}
Conducting single frame orthorectification on satellite images to create an ortho-image requires four basic components, namely an image, a geometric sensor model, elevation data (for example a digital elevation model (DEM)) and ground control points (GCPs). For this study, orthorectification entailed the use of a single scene Pléiades primary panchromatic image, applying the Pleiades rigorous geometric model, utilising a high-quality $2 \mathrm{~m} \mathrm{DEM}$ and using GCPs that were acquired from two different collection methods. The application of these different GCPs to the execution of orthorectification encompassed the aim of this paper, which was to investigate and compare the positional accuracies of ortho-images under two scenarios. Firstly, GCPs were manually collected through fieldwork utilising a Trimble GeoExplorer 6000 series handheld GPS device and secondly, by utilising TerraSAR-X based GCPs that were acquired from Airbus Defence and Space. The objective of this study was to determine the geolocation accuracy of a highresolution satellite ortho-image when different types of ground control are used. This required the execution of two orthorectification tests where only the type of GCPs differed. The results of these tests were interesting since it highlighted the difference in positional accuracy when utilising various sources of ground control to perform orthorectification on satellite imagery. The comparison results showed that utilising the manual GCPs produced a better positional accurate ortho-image as opposed to using the TerraSAR-X based GCPs. Nonetheless, the TerraSAR-X based GCPs still produced a sub $2 \mathrm{~m}$ accurate ortho-image, which is more than sufficient for the production of most geospatial products.
\end{abstract}

Keywords: orthorectification, digital elevation model (DEM), ground control point (GCP), highresolution satellite imagery, TerraSAR-X based GCPS, WorldDEM ${ }^{\mathrm{TM}}$, Airbus Defence and Space.

\section{Introduction}

The geometric correction of satellite imagery has been a pivotal topic since the launch of the first Earth observation satellite system in the 1960's. Various methods exist to perform geometric 
correction, such as georectification and georeferencing methods which focus on the horizontal position of image pixels. In contrast, orthorectification consider the pixel positional shift caused by the Earth's curvature and provides real ground coordinates ( $\mathrm{x}, \mathrm{y}$ and $\mathrm{z}$ values) for all pixels. The conditions and data sources to use when performing orthorectification on high-resolution satellite imagery to achieve a certain level of geometric accuracy are in literature well known, but in practice it is more difficult to meet all conditional requirements. An ortho-image is only as accurate as the input and reference sources used, such as the use of digital elevation models (DEMs) and ground control points (GCPs). The collection of suitable GCPs presents a significant problem, as existing sources of GCPs may not be publicly available. However, DEMs are either easily available as precise and fine scale products that can be obtained from commercial suppliers (e.g. Airbus Defence and Space), for example the WorldDEM ${ }^{\mathrm{TM}}$ product (12 $\mathrm{m}$ resolution) or available as public products such as (Rexes and Hirt, 2014):

a) Shuttle Radar Topography Mission (SRTM): available as 1 arc-second resolution (30 m) and 3 arc-second resolution $(90 \mathrm{~m})$;

b) Digital Terrain Elevation Data (DTED): resolution is available in levels 0 (900 m), $1(90 \mathrm{~m})$ and $2(30 \mathrm{~m})$; and

c) Advanced Spaceborne Thermal Emission and Reflection Radiometer (ASTER) Global Digital Elevation Map (GDEM): available in $30 \mathrm{~m}$ resolution.

The theoretical basis to perform orthorectification on satellite imagery is well documented in the literature (Petrat and Eloff, 2014, Maxwell et al., 2014, Stampoulidis, 2014). It is inevitable that remotely sensed imagery will inherit geometric distortions during data capturing, due to many influential factors that affect the positional accuracy of satellite imagery. Factors such as acquisition geometry, topographic properties of the image area, optical fidelity of the sensor and positional steadiness all play a vital role in the extent of geometric errors imbedded in remotely sensed imagery (Toutin, 2004, Jacobsen, 2002). Richards and Xiuping (2006) states that geometric correction, known as image rectification, rectifies positional distortions or errors in satellite imagery that are caused by sensor-Earth geometry variations. The application of image rectification entails the method of converting image coordinates to real-world coordinates on the Earth's surface (Yang and Williams, 1997). Orthorectification is the process that eliminates the geometric distortions introduced during image acquisition caused by topographic relief, lens distortions and camera tilt. It produces a planimetric image that has a consistent image scale and which can be accurately registered to real-world map projections (Gao, 2008).

Traditionally, orthorectification was a semi-automated process that required user inputs regarding the sensor platform, GCPs and terrain elevation to process the image data accurately using image processing software. However, with the recent development of newly designed sensor systems this traditional approach has changed dramatically. Automated orthorectification of imagery is now possible based on the comprehensive metadata embedded in remotely sensed data and by utilising new and improved sensor models and algorithms to process the image data (Hoja et al., 2008, Jacobsen et al., 2005, Toutin, 2006). The modernisation of satellite systems brought about 
a new and improved dimension to the pointing accuracies of current and future generations of satellite systems (Petrat and Eloff, 2014, Dial and Grodecki, 2005). Currently, orthorectifications are more and more performed by using rational polynomial coefficients (RPCs), elevation data and optional GCPs to achieve highly accurate ortho-images, due to the fact that not all $3^{\text {rd }}$ party image processing software have extended sensor model libraries to include all rigorous sensor models. The RPC method is a coordinate transformation that converts pixel coordinates of the satellite image to latitude and longitude coordinates relating to an elevation data source covering the same scene on the Earth (Okeke, 2010).

This method of using RPCs (non-parametric approach) employs simpler empirical mathematical models, compared to using rigorous sensor models (parametric approach) which entails complicated mathematical modelling (Dial and Grodecki, 2005). The non-parametric approach is usually followed due to the lack of suitable auxiliary data such as the non-availability of sensor specific parameters. However, when highly accurate ortho-images are required and auxiliary data are readily available, then the use of rigorous sensor models will be the most suitable option. Most ortho-image applications require very high registration accuracy. For instance, a registration error of less than $1 / 5$ of a pixel will produce a change detection error of less than $10 \%$ and for measurement accuracies of less than $1 \mathrm{~m}$ (e.g. measurements of ice flow and cosmic ground deformation) even better registration accuracy is required (Leprince et al., 2007). In practice, the acquisition of raw image data with detailed sensor information and sufficient elevation data to achieve high registration accuracy is not problematic. However, the collection of ground control points poses a significant problem when performing single frame orthorectification. The objectives of this paper are to compare the positional accuracies of ortho-images created by utilising two different GCP collection/acquisition scenarios:

a) Firstly, using GCPs that were manually collected through fieldwork utilising a Trimble GeoExplorer 6000 series handheld GPS receiver device (model: GeoXH 3.5G) and

b) Secondly, using TerraSAR-X-based GCPs that were acquired from Airbus Defence and Space.

The study area identified for conducting the orthorectification tests was the City of Tshwane, which is located within the South African borders (Figure 1). The City of Tshwane area was deliberately selected to be the study area to perform the orthorectification tests, because this area is characterised by a diverse topographical layout with up to $375 \mathrm{~m}$ between the lowest and highest locations. This layout of the land ranges from mountainous areas to relative flat plateaus, characterised by typical urban activities and land uses. It also made logistical and economic sense to conduct the study close to where the researcher resides due to the required field data collection and verification activities. 


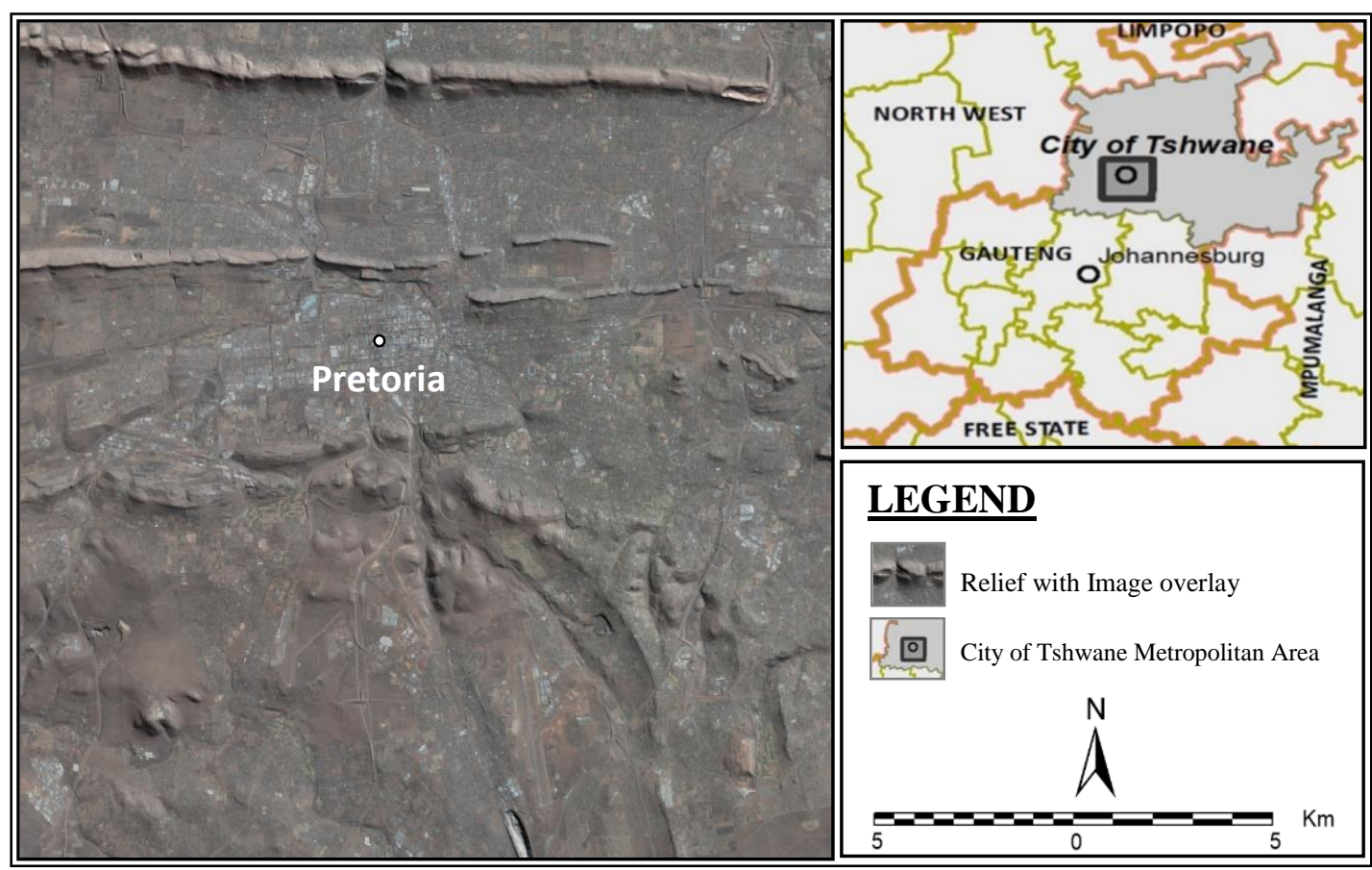

Figure 1. Geographical study area in the City of Tshwane Metropolitan Area

\section{Datasets Applied}

\subsection{Satellite based image data}

This study was conducted by utilising a Pléiades primary panchromatic image which was acquired from Airbus Defence and Space. This image has a spatial resolution of $50 \mathrm{~cm}$ and covers an area of approximately $400 \mathrm{~km}^{2}$. The Pléiades primary product can be described as the processing level closest to the natural image acquired by the sensor. This product restores perfect collection conditions, in other words, the sensor is placed in rectilinear geometry and the image is clear of all radiometric distortions (Airbus Defence and Space, October 2012). The primary product is based on the Digital Image Map (DIMAP) Version 2 structure and consists various auxiliary files (Panem et al., 2012). The DIMAP format is a public format for describing geographical data.

\subsection{Ground control points}

\subsubsection{GPS device based GCP collection}

A manual collection of 25 GCPs were captured using a Trimble GeoExplorer 6000 series handheld (GeoXH 3.5G) device. The Trimble GeoExplorer 6000 series handheld GPS device uses both EVEREST and H-Star technology to obtain $10 \mathrm{~cm}$ accuracy during real-time operation or after post-processing (Trimble, February 2011).

South African TrigNet data were utilised to achieve extremely accurate GCPs after postprocessing. TrigNet consists of Global Navigation Satellite Systems (GNSS) base stations that are permanently and continuously in operation to record 1-second epoch data on both L1 and L2 GPS 
frequencies. These data are streamed in real-time to the TrigNet control centre situated in the offices of the Chief Directorate: National Geospatial Information located in the Western Cape.

In South Africa, there are currently three TrigNet Network Real Time Kinematic (RTK) solutions generated within a Virtual Reference Station (VRS) network available within the Western Cape, Gauteng and Kwa-Zulu Natal provinces (Figure 2). The following real-time data are provided (National Geospatial Information, 2014a):

a) Differential GPS (DGPS) at $\sim 35 \mathrm{~cm}$,

b) RTK at $\sim 5 \mathrm{~cm}$ and

c) Network RTK at $\sim 3 \mathrm{~cm}$.

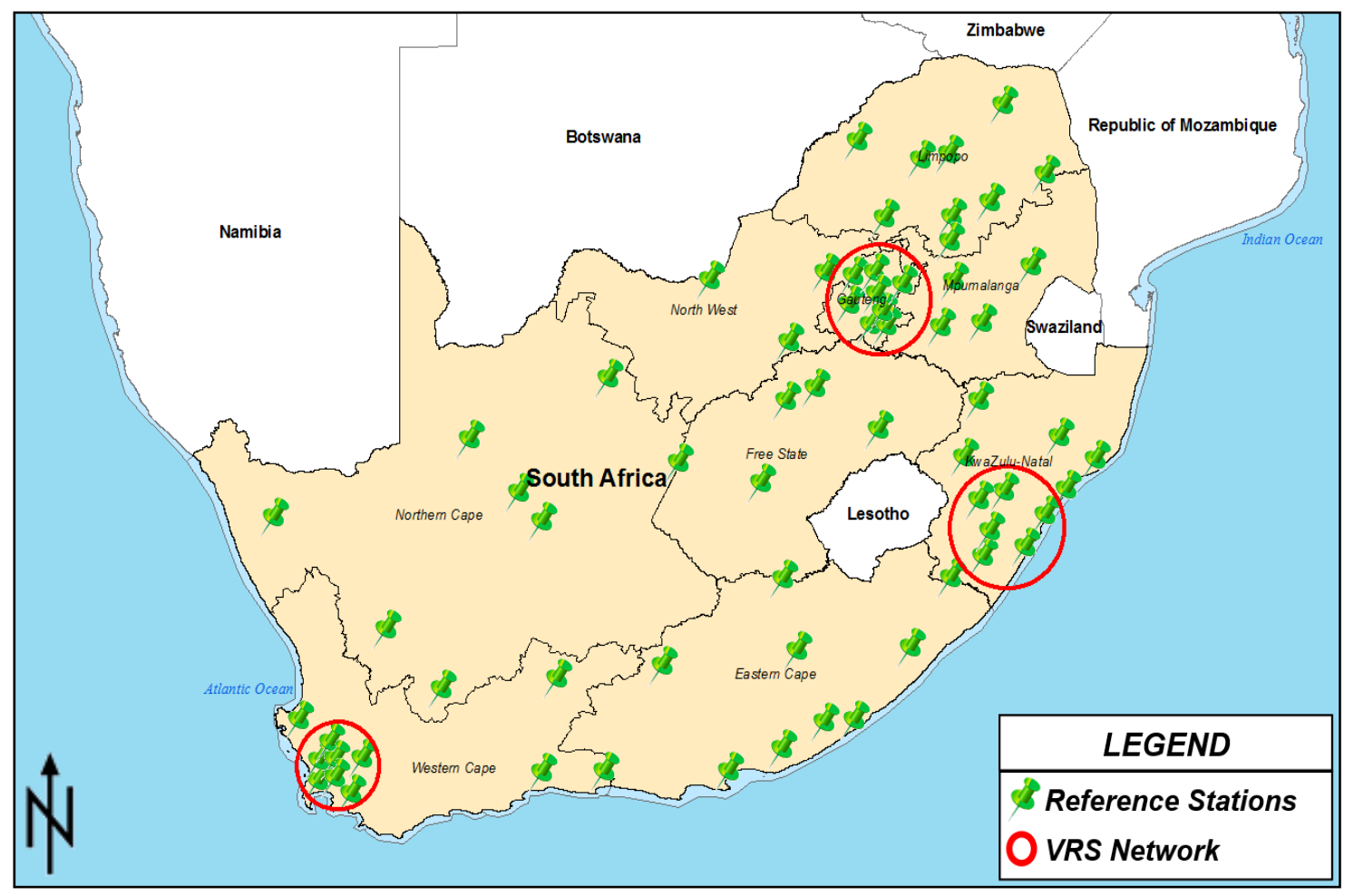

Figure 2. South African TrigNet Stations (Copyright 2014, Trimble Navigation Limited)

Adapted from National Geospatial Information (2014b)

The distribution of the manually collected GCPs were pre-determined by identifying the precise locations on the Earth's surface where the GCPs need to be collected. This was done by evaluating the satellite based image data of the geographical area of interest in order to achieve a uniform distribution of GCPs covering the entire sample area (Figure 3). The centre and four corners of the image were used as the starting point for determining the position of the GCPs. Post-processing of the GCPs consisted of differential correction by utilising the TrigNet Pretoria GNSS data as the base and reference provider. One-second epoch data were downloaded in Receiver Independent Exchange (RINEX) format from the TrigNet Web Application for the specific period during the capturing of the GCPs. The post-processing was performed by importing the data into the Trimble Pathfinder Office 5.6 software. 
South African Journal of Geomatics, Vol. 5. No. 3, November 2016

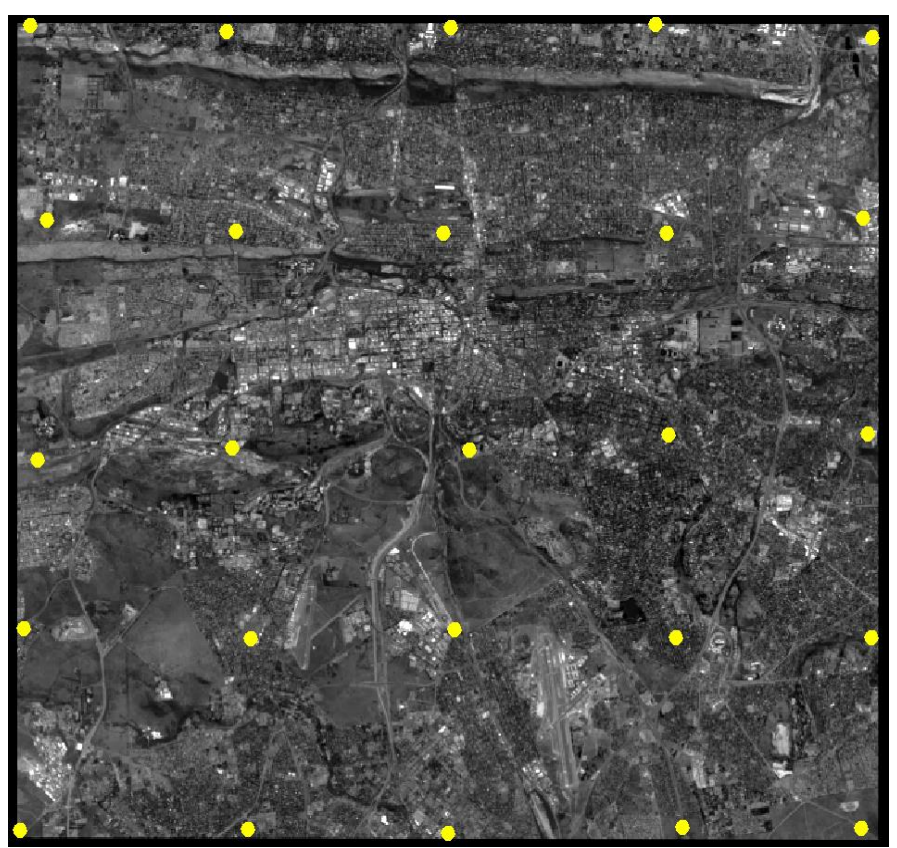

Figure 3. GPS device based GCPs distribution

(Copyright @ CNES 2013, Distribution Airbus Defence and Space / SPOT Image, all rights reserved)

The accuracy results of the GCPs achieved from performing the post-processing shows that $85.63 \%$ of all GCPs have a 3-D (vertical and horizontal) positional accuracy between $5-50 \mathrm{~cm}$ and $14.37 \%$ of the GCPs have a 3-D positional accuracy between $0.5-1.0 \mathrm{~m}$ (Figure 4). It can therefore be stated that all GCPs have a positional accuracy of less than $1.0 \mathrm{~m}$ and since $85 \%$ of all GCPs have an accuracy of less than $50 \mathrm{~cm}$, the error measurements considered during this study are $50 \mathrm{~cm}$ with a Circular Error probability of $85 \%$ (CE85).

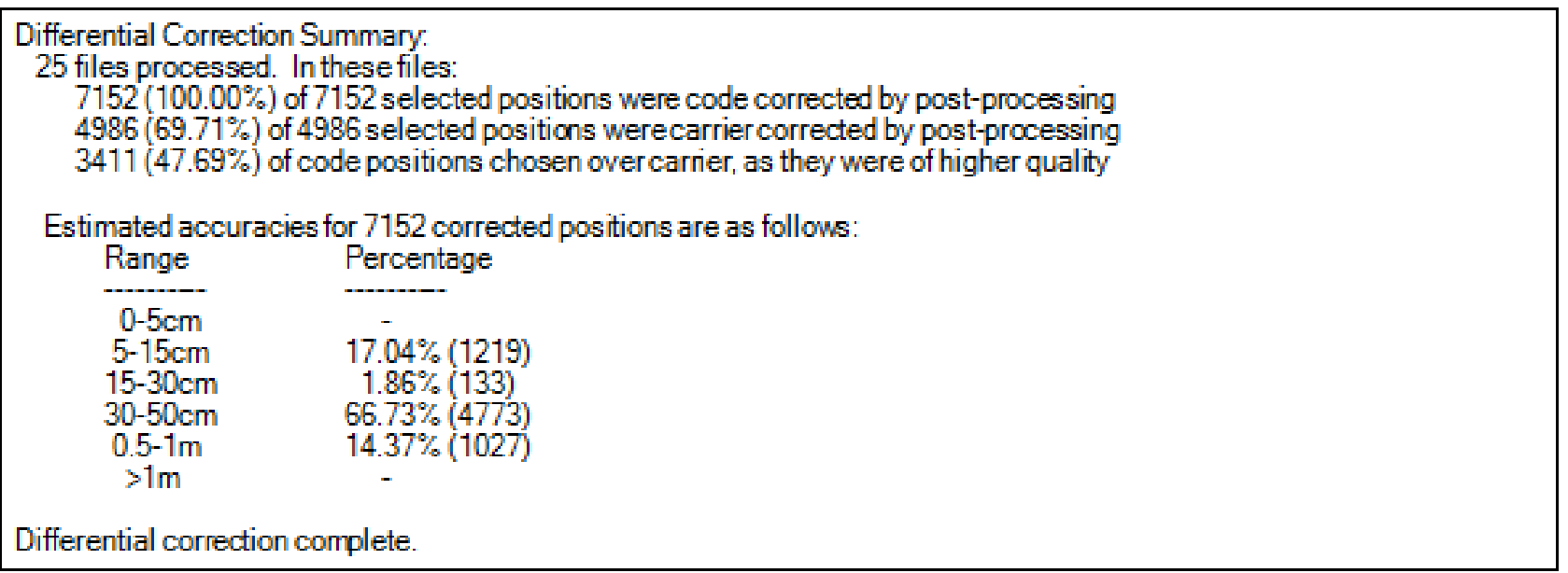

Figure 4. Differential correction summary

\subsubsection{TerraSAR-X collected GCPS}

The TerraSAR-X satellite provides accurate and outstanding quality GCPs from space. The accuracy of these GCPs is achieved based on the TerraSAR-X orbit accuracy, the precise radar X- 
band beam, its high-resolution and location accuracy of the imagery, which is up to $0.25 \mathrm{~m}$ in range and azimuth for both Staring Spotlight and Stripmap products. In a study conducted by Hummel (2011), using HR Spotlight scenes acquired from a four-flight TerraSAR-X data acquisition flightplan, it is stated that TerraSAR-X GCPs are delivered with an unrivalled accuracy where GCPs have a horizontal accuracy of $1.0 \mathrm{~m}$ and a vertical accuracy of $0.5 \mathrm{~m}$.

These accuracies were achieved by measuring the data against GPS measurements and the precise coordinates of corner-reflectors in a very diverse topographical area. TerraSAR-X-based GCPs are delivered as two standard accuracy products (Airbus Defence and Space, 2016), namely:

a) TerraSAR-X GCP-1: multiple Spotlight scenes are used to extract 5 GCPs with an accuracy of approximately $1 \mathrm{~m}$, covering an area of roughly $20 \mathrm{~km}^{2}$.

b) TerraSAR-X GCP-3: multiple Stripmap acquisitions are used to deliver 10 GCPs with an accuracy of approximately $3 \mathrm{~m}$, covering an area of roughly $1000 \mathrm{~km}^{2}$.

This study used the TerraSAR-X GCP-3 product. Airbus Defence and Space was requested to provide a random distribution of the 10 points that covers the entire $400 \mathrm{~km}^{2}$ sample area (Figure 5) to create a near ideal distribution for creating an ortho-image.

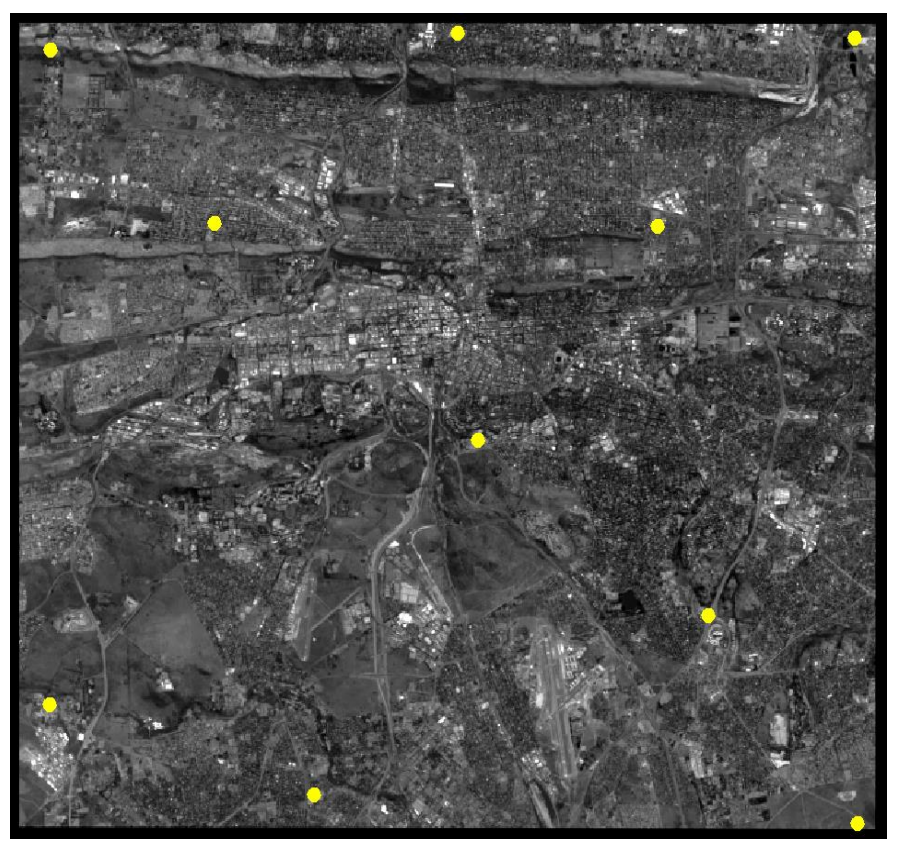

Figure 5. TerraSAR-X GCP-3 distribution

(Copyright (C) CNES 2013, Distribution Airbus Defence and Space / SPOT Image, all rights reserved)

It is stated in the TerraSAR-X GCP-3 Coordinate Specification and Accuracy Assessment file that was received from Airbus Defence and Space on 18 August 2014 for this study that the accuracy of each of the 10 GCPs acquired are $1 \mathrm{~m}$ for $\mathrm{x}, \mathrm{y}$ and $\mathrm{z}$ locations (Table 1). This is very good accuracy to achieve from multiple Stripmap acquisitions, which is equivalent to the stated TerraSAR-X GCP-1 product accuracy. 
South African Journal of Geomatics, Vol. 5. No. 3, November 2016

Table 1. TerraSAR-X GCP-3 coordinate specification and accuracy assessments

\begin{tabular}{|c|c|c|c|c|c|c|c|c|}
\hline \multirow{2}{*}{$\begin{array}{c}\text { Point } \\
\text { ID }\end{array}$} & \multicolumn{2}{|c|}{$\begin{array}{c}\text { UTM } \\
\text { (m) }\end{array}$} & \multirow{2}{*}{$\begin{array}{c}\text { Ellipsoid } \\
\text { Height } \\
\text { (m) }\end{array}$} & \multirow{2}{*}{$\begin{array}{l}\text { UTM } \\
\text { Zone }\end{array}$} & \multirow{2}{*}{$\begin{array}{l}\text { Latitude } \\
\text { (DD) }\end{array}$} & \multirow{2}{*}{$\begin{array}{c}\text { Longitude } \\
\text { (DD) }\end{array}$} & \multicolumn{2}{|c|}{$\begin{array}{l}\text { Accuracy } \\
\text { (m) }\end{array}$} \\
\hline & Easting & Northing & & & & & Horizontal & Vertical \\
\hline 1 & 629581.679 & 7139801.673 & 1527.505 & $35 \mathrm{~S}$ & -25.85440758 & 28.29315271 & 1 & 1 \\
\hline 2 & 610787.24 & 7158649.929 & 1458.289 & $35 \mathrm{~S}$ & -25.68578606 & 28.10404905 & 1 & 1 \\
\hline 3 & 629691.94 & 7158772.17 & 1284.251 & $35 \mathrm{~S}$ & -25.68313520 & 28.29239641 & 1 & 1 \\
\hline 4 & 620748.943 & 7149146.143 & 1402.556 & $35 \mathrm{~S}$ & -25.77080309 & 28.20416964 & 1 & 1 \\
\hline 5 & 620354.913 & 7158978.25 & 1275.77 & $35 \mathrm{~S}$ & -25.68206919 & 28.19934997 & 1 & 1 \\
\hline 6 & 614590.54 & 7154449.11 & 1329.238 & $35 \mathrm{~S}$ & -25.72342109 & 28.14230690 & 1 & 1 \\
\hline 7 & 626106.521 & 7144871.115 & 1531.991 & $35 \mathrm{~S}$ & -25.80894594 & 28.25799534 & 1 & 1 \\
\hline 8 & 625004.879 & 7154260.968 & 1330.711 & $35 \mathrm{~S}$ & -25.72426897 & 28.24612224 & 1 & 1 \\
\hline 9 & 616815.37 & 7140615.775 & 1464.359 & $35 \mathrm{~S}$ & -25.84813641 & 28.16570215 & 1 & 1 \\
\hline 10 & 610634.665 & 7142848.078 & 1402.269 & $35 \mathrm{~S}$ & -25.82846428 & 28.10384714 & 1 & 1 \\
\hline
\end{tabular}

\subsubsection{Digital Elevation Model}

The DEM used in this study was derived from LiDAR data collected over the entire City of Tshwane during August 2013 (Figure 6).

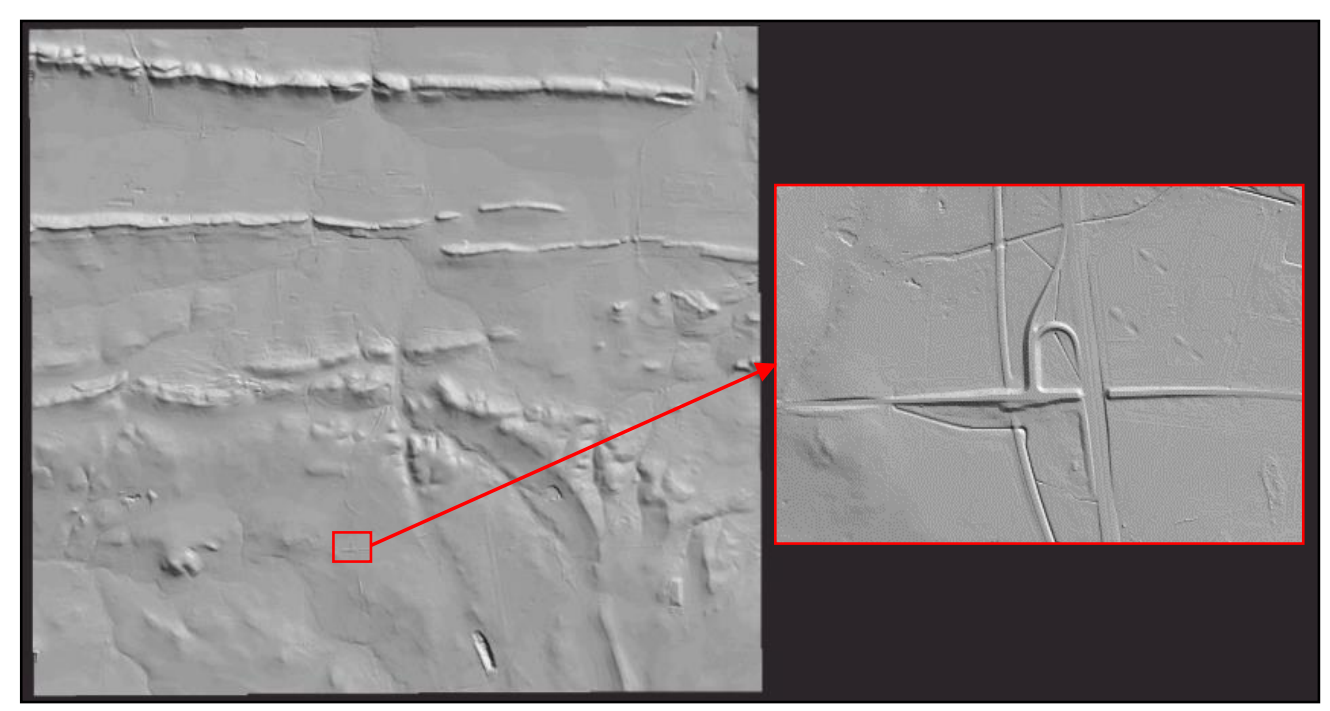

Figure 6. DTM with $2 \mathrm{~m}$ spatial resolution created from LiDAR point data

Captured at \pm 8 observations per square meter using a Leica ALS50 sensor and thirty percent overlap, the point cloud returns were subsequently classified into ground and non-ground layers. These classified $\mathrm{x}, \mathrm{y}$, and $\mathrm{z}$ measurements (ground and non-ground) formed the primary input when generating both a seamless 32-bit DTM and DSM base product at two meter Ground Sample Data. This was achieved mainly by executing the well-known ANUDEM algorithm (Hutchinson, 2011) and other DEM quality enhancements, such as terrain filtering, interpolation and removing noise (e.g. spikes and sinks). It is stated in the ANUDEM Version 5.3 User Guide (Hutchinson, 2011) that the ANUDEM a program is which was developed by Professor M. F. Hutchinson (Professor of 
Spatial and Temporal Analysis, Fenner School of Environment and Society, Australian National University, Canberra). It "calculates values on a regular grid of a discretised smooth surface fitted to large numbers of irregularly spaced elevation data point, contour lines, streamlines, sink points, lake boundaries and cliff lines. The program imposes a global drainage condition that automatically removes spurious sinks where possible."

\section{Methodology}

\subsection{Software}

It is important to realise that no processing or analysis of satellite imagery can be performed without the use of appropriate image processing software. This software enables the import, store, retrieve, manipulation, processing and analyses of the satellite imagery. There are various commercial (e.g. PCI Geomatica, ERDAS IMAGINE and ENVI) and open source (e.g. Orfeo Toolbox) Geographic Information Systems (GIS) and image processing systems available for working with image data and performing orthorectification. To perform orthorectification using these types of software requires the application of specific photogrammetry tools and functions that consist of all important geometric sensor models to manipulate or alter input parameters and input sources as required (Chmiel et al., 2004). For this study, the ERDAS IMAGINE 2015 image processing system was selected to perform the orthorectification tests, due to the fact of the extensive knowledge and skills acquired over numerous years in operating this system. This system includes all necessary transform and ortho-correct tools and functionalities as well as a Photogrammetry module to work with high-quality 3D data.

\subsection{Orthorectification tests}

The two scenarios described in Section 1 were executed by performing two orthorectification tests. Both tests were conducted by utilising a very high-quality elevation data source that was derived from a Light Detection and Ranging (LiDAR) point dataset to create the $2 \mathrm{~m}$ digital terrain model (DTM), described in Section 2.2.3.

Test 1 was executed by utilising 25 GCPs that were evenly distributed across the entire image scene and the elevation source, previously mentioned. The GCPs consisted of ground control that were collected with the use of a GPS device, as explained in Paragraph 2.2.1 and the location of the GCPs was predetermined to ensure an even and uniform distribution across the image.

Test 2 was executed using the already mentioned 10 TerraSAR-X based GCPs. These GCPs are also evenly distributed across the entire image scene and the same $2 \mathrm{~m}$ elevation source is used as in Test 1.

Both these tests utilised the Pléiades rigorous geometric model to perform orthorectification. This model is sensor specific and requires the input of internal and external orientation parameters which are distributed by image vendors in the form of image acquisition metadata that are usually 
included in raw image delivery packages or as an occupying file with certain processing level products. These types of sensor models can be described as 2D/3D physical and deterministic models that consists of complicated mathematical modelling algorithms for considering physical geometry components (Toutin, 2004). These mathematical equations are based on collinearity equations, which include parameters for camera timing, alignment, focal plane and satellites altitude and ephemeris (Aguilar et al., 2008). Collinearity equations (Liang et al., 2012) refer to a set of two equations to transmit sensor coordinates (2D) to object coordinates (3D).

The results of both these tests were analysed in terms of the RMSE achieved as well as based on measurements received from utilising the ERDAS IMAGINE 2015 Metric Accuracy Assessment (MAA) tool.

a) RMSE: to calculate RMSE, known GCP coordinates are compared to retransformed coordinates of the same points of the introduced reference GCPs by calculating a transformation matrix (a set of numbers computed from the GCPs that can be plugged into polynomial equations) from the GCPs (Hexagon Geospatial, 2015). The reference GCPs are converted to the input coordinate system and the distance between these retransformed coordinates and the original input coordinates is the RMSE (Hexagon Geospatial, 2015). The ERDAS IMAGINE 2015 software reports the RMSE for each respective GCP and indicates the total RMSE when utilising the GCP tool.

b) MAA tool: this tool allows the user to utilise control points (CPs) to measure and report the accuracy of an image. Each control point entered is measured by calculating the error between the image coordinates and coordinates of the matching $\mathrm{CP}$. This report contains the errors and statistics of each measured individual point, illustrated below by Figures 7 and 8 .

\section{Results and Discussion}

\subsection{Test 1 - Orthorectification utilising 25 manually collected GCPs}

The RMSE achieved from performing Test 1 was measured at $0.632 \mathrm{~m}$ and the MAA report created for this test, indicates an accuracy of $0.718 \mathrm{~m}$ (Figure 7).

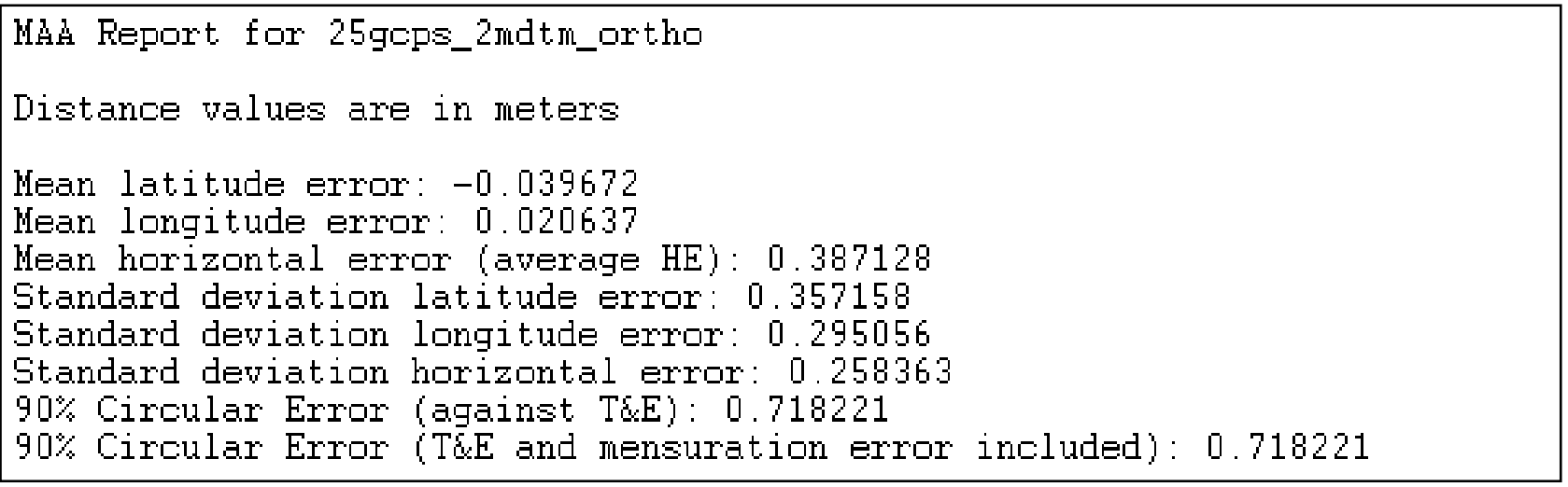

Figure 7. MAA report for ortho-image created from utilising 25 manually collected GCPs 


\subsection{Test 2 - Orthorectification utilising TerraSAR-X GCP-3 product}

The RMSE achieved from conducting Test 2 was $1.61 \mathrm{~m}$. The MAA tool indicates that an accuracy of $1.821 \mathrm{~m}$ was achieved (Figure 8).

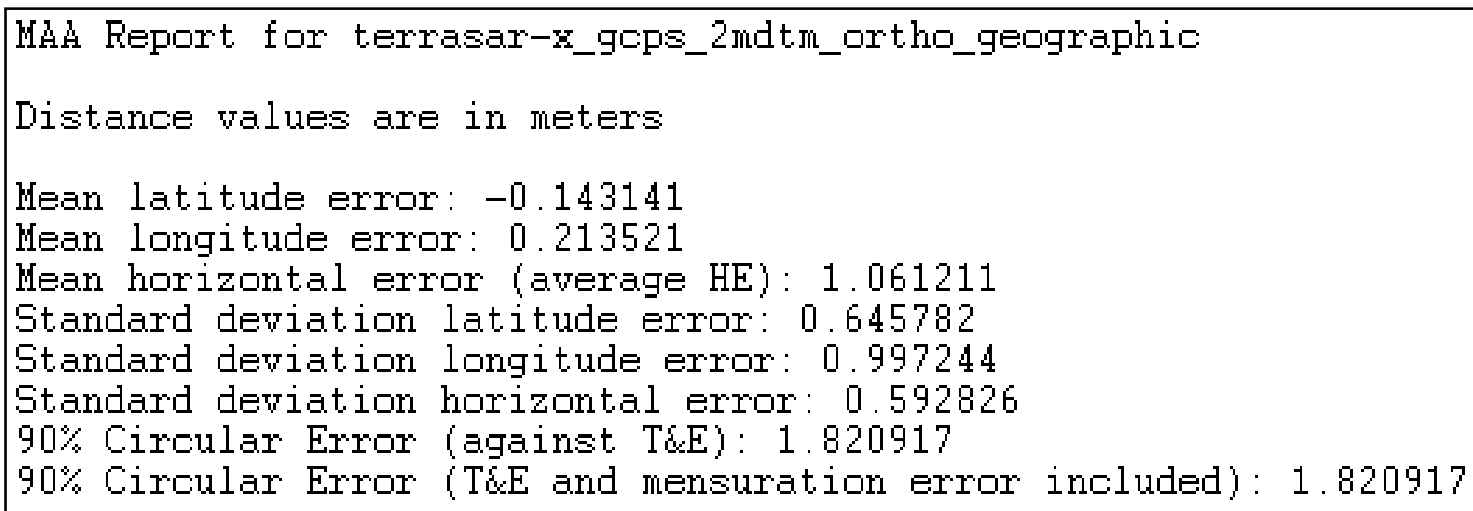

Figure 8. MAA report for ortho-image created from utilising 10 TerraSAR-X-based GCPs

In the first test, 25 manually collected GCPs were provided to the model and for the second test, 10 automatically acquired GCPs, extracted from the TerraSAR-X satellite. Both tests had an even distribution of GCPs that covered the entire sample area. It is evident by comparing Figure 7 with Figure 8 that utilising 25 GCPs (GPS device based GCP collection) yielded a more accurate orthoimage than utilising only 10 GCPs (TerraSAR-X collected GCPs), even though the same elevation source was used. The geolocation accuracies (metres) are summarised in Table 2. The measurements indicate the following accuracy results (Figure 9):

a) RMSE: the RMSE of the ortho-images are $0.632 \mathrm{~m}$ for Test 1 and $1.609 \mathrm{~m}$ for Test 2.

b) MAA tool: the MAA measured deviations are $0.718 \mathrm{~m}$ for Test 1 and $1.821 \mathrm{~m}$ for Test 2 .

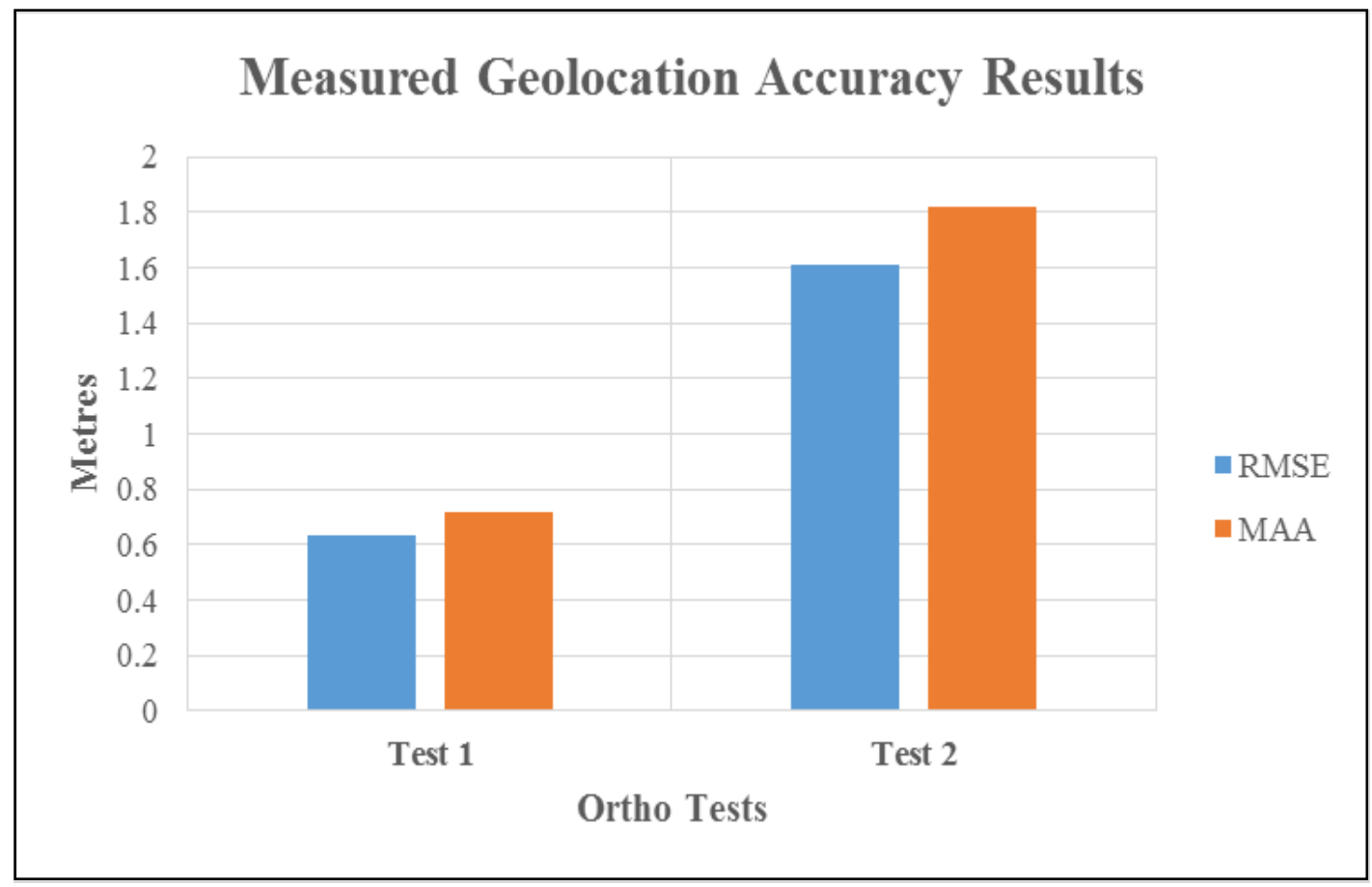

Figure 9. Measured geolocation accuracy results 
The fact that the majority of the 25 manually collected GCPs had a positional error of less than $50 \mathrm{~cm}$ CE85 (see Section 2.2.1 and Figure 4) compared to the $1 \mathrm{~m}$ of the TerraSAR-X-based GCPs (see Section 2.2.2) made a significant difference in the location accuracies of the ortho-images.

Table 2. Comparison of geolocation accuracies for GCPs and CP

\begin{tabular}{|c|c|c|c|c|c|c|c|c|c|c|c|c|}
\hline \multirow{3}{*}{$\begin{array}{l}\text { Ortho } \\
\text { Tests }\end{array}$} & \multicolumn{7}{|c|}{ GCP Measurements } & \multicolumn{5}{|c|}{ CP Measurement } \\
\hline & \multicolumn{2}{|c|}{$\begin{array}{l}\text { Residual } \\
\quad \text { (m) }\end{array}$} & \multirow{2}{*}{$\begin{array}{c}\text { RMSE } \\
\text { (m) }\end{array}$} & \multicolumn{2}{|c|}{$\begin{array}{c}\text { Min } \\
(\mathbf{m})\end{array}$} & \multicolumn{2}{|c|}{$\begin{array}{c}\text { Max } \\
(\mathbf{m})\end{array}$} & \multicolumn{2}{|c|}{$\begin{array}{c}\text { Mean } \\
(\mathbf{m})\end{array}$} & \multicolumn{2}{|c|}{$\begin{array}{c}\text { Standard } \\
\text { Deviation } \\
\text { (m) }\end{array}$} & \multirow{2}{*}{$\begin{array}{r}\text { MAA } \\
\text { (m) }\end{array}$} \\
\hline & $\mathbf{x}$ & $\mathbf{y}$ & & $\mathbf{x}$ & $\mathbf{y}$ & $\mathbf{x}$ & $\mathbf{y}$ & $\mathbf{x}$ & $\mathbf{y}$ & $\mathbf{x}$ & $\mathbf{y}$ & \\
\hline Test 1 & 0.804 & 0.975 & 0.632 & -2.053 & -1.819 & 2.470 & 2.920 & 0.021 & -0.039 & 0.295 & 0.357 & 0.718 \\
\hline Test 2 & 2.197 & 1.609 & 1.609 & -5.253 & -3.490 & 3.617 & 4.053 & 0.214 & -0.143 & 0.997 & 0.645 & 1.821 \\
\hline
\end{tabular}

When comparing the results of these tests, it is evident that both ortho-images were produced with a very high relative accuracy. However, there is a significant difference in the absolute accuracy between these images. Utilising more GCPs with higher accuracy and distribution, does create a more accurate ortho-image. A practical point that can be highlighted is that when it is suitable to collect well distributed GCPs manually over the project area then a very accurate result can be expected, yet it is also important to note that if it is not possible/practically to achieve the latter, satellite based GCP collection do provide a very good alternative.

\section{Conclusion}

This article studied the influence of two types of GCP collection methods on the accuracy of orthorectification based on the parametric approach. One collection was based on a manual field based GCP collection and the other satellite based collection. Both tests made use of the same elevation source, which allowed for determining the effect of the geolocation accuracy of the orthoimage based only on the GCP collection method, distribution and number.

The first test made use of 25 GCPs that were collected during fieldwork with the use of a GPS device. The locations of these GCPs were pre-determined through evaluating the sample area to acquire a uniform distribution of the entire area. The accuracy of these GCPs was determined to be $50 \mathrm{~cm}$ (CE85). The ortho-image produced from using these GCPs had a RMSE of $0.632 \mathrm{~m}$ and a geolocation accuracy of $0.718 \mathrm{~m}$.

The second test was performed with the use of 10 GCPs, evenly distributed to cover the sample area, that were acquired from Airbus Defence and Space. The TerraSAR-X based GCPs used during this test are claimed to have a horizontal and vertical accuracy of $1 \mathrm{~m}$ (Airbus Defence and Space, 2016). This test created an ortho-image with a RMSE of $1.609 \mathrm{~m}$ and a geolocation accuracy of $1.821 \mathrm{~m}$. 
It is evident from the results that the GPS device based GCP collection method produced a better geolocation accuracy ortho-image as compared to the TerraSAR-X automatic GCP collection method. However, it should be noted that manually collecting new GCPs for a specific area might be an expensive exercise. In some cases, areas are inaccessible, which make it impossible to collect new GCPs due to environmental conditions, security and mobility restrictions. In such cases, the acquisition of TerraSAR-X based GCPs will be a feasible alternative. TerraSAR-X produces unrivalled accuracies of $1 \mathrm{~m}$ and $3 \mathrm{~m}$ for the two automatic extracted GCP products available, as was indicated by this study. Therefore, in the event of producing a highly accurate ortho-image, the GPS device based GCP collection method should prevail, but the TerraSAR-X-based GCPs can certainly be used as an alternative to manually collecting GCPs using a GPS device.

\section{Acknowledgements}

The work contained in this article was done as part of my Ph.D studies in Geoinformatics at the Department of Geography, Geoinformatics and Meteorology, University of Pretoria (Henrico, 2016). Special thanks to my promoter, Prof. Ludwig Combrinck (extraordinary staff member of the University of Pretoria, Acting Director HartRAO) and Dr. Corné Eloff (Airbus Defence and Space, Geo-Intelligence) for their insight and support towards this study. I extend my gratitude to Mr. Frank Hensler (Business Development Manager TerraSAR-X Services: Airbus Defence and Space / Infoterra $\mathrm{GmbH}$ ) for his continuous support and cooperation in providing the TerraSAR-X GCPs that were utilised during this study. I would also like to thank the Director, City of Tshwane Metropolitan Municipality - Corporate GIS / City Planning and Development Department for making their LiDAR data available and specifically Mr. André Breytenbach (Build Environment) from The Council for Scientific and Industrial Research (CSIR) for his support and insight regarding the elevation data sources utilised during this study.

\section{References}

Aguilar, M., Agüera, F., Aguilar, F. and Carvajal, F. 2008. Geometric accuracy assessment of the orthorectification process from very high resolution satellite imagery for Common Agricultural Policy purposes. International journal of remote sensing, 29, 7181-7197.

Airbus Defence and Space. 2016. TerraSAR-X-based Ground Control Points [Online]. Available: http://www.astrium-geo.com/en/134-terrasar-x-based-ground-control-points. [Accessed 12 May 2014].

Airbus Defence and Space. October 2012. Pleiades Technical Documents: Pleiades User Guide. 2.0. Available: http://geo-airbusds.com/en/4572-pleiades-technical-documents [Accessed 26 March 2015].

Chmiel, J., Kay, S. and Spruyt, P. Orthorectification and geometric quality assessment of very high spatial resolution satellite imagery for Common Agricultural Policy purposes. Proceedings of XXth ISPRS Congress, 2004. 12-23.

Dial, G. and Grodecki, J. 2005. RPC replacement camera models. The International Archives of the Photogrammetry, Remote Sensing and Spatial Information Sciences, 34.

Gao, J. 2008. Digital analysis of remotely sensed imagery, New York, McGraw-Hill Professional. 
South African Journal of Geomatics, Vol. 5. No. 3, November 2016

Hexagon Geospatial. 2015. ERDAS Imagine Help Guide [Online]. Available: https://hexagongeospatial.fluidtopics.net/book\#!book;uri=f2790e0ca81311531f1a57c6b7bc8 0b2;breadcrumb=463fdbd554b442e712f3960796bf66ca [Accessed 08 March 2016].

Hoja, D., Schneider, M., Müller, R., Lehner, M. and Reinartz, P. 2008. Comparison of orthorectification methods suitable for rapid mapping using direct georeferencing and RPC for optical satellite data. The International Archives of the Photogrammetry, Remote Sensing and Spatial Information Sciences, 37, 1617-1624.

Hummel, P. 2011. Remotely Sensed Ground Control Points: Field tests verify accuracy of satellite imagery. Available: http://www.compassdatainc.com/newsroom/TIM\%20edited\%20v9.pdf [Accessed 12 May 2014].

Hutchinson, M. F. 2011. ANUDEM Version 5.3. User Guide, (Revision: 09 August 2011), The Australian National University, Centre for Resource and Environmental Studies, Canberra.

Jacobsen, K. 2002. Geometric aspects of the handling of space images. International archives of photogrammetry remote sensing and spatial information sciences, 34, 89-93.

Jacobsen, K., Büyüksalih, G. and Topan, H. 2005. Geometric models for the orientation of high resolution optical satellite sensors. The International Archives of the Photogrammetry, Remote Sensing and Spatial Information Sciences, 36, 1.

Leprince, S., Barbot, S., Ayoub, F. and Avouac, J. P. 2007. Automatic and precise orthorectification, coregistration, and subpixel correlation of satellite images, application to ground deformation measurements. Geoscience and Remote Sensing, IEEE Transactions on, $45,1529-1558$.

Maxwell, A., Strager, M., Warner, T., Zegre, N. and Yuill, C. 2014. Comparison of NAIP orthophotography and RapidEye satellite imagery for mapping of mining and mine reclamation. GIScience \& Remote Sensing, 51, 301-320.

National Geospatial Information. 2014a. Trignet Web Application [Online]. Available: http://www.trignet.co.za [Accessed 25 June 2014].

National Geospatial Information. 2014b. Trignet Web Application: Sensor Map [Online]. Available: www.trignet.co.za/Map/SensorMap.aspx [Accessed 17 July 2014].

Okeke, F. I. 2010. Review of digital image orthorectification techniques. Available: http://gisdevelopment.net/technology/ip/fiopf.htm [Accessed 28 July 2016].

Panem, C., Bignalet-Cazalet, F. and Baillarin, S. 2012. Pleiades-HR system products performance after in-orbit commissioning phase. Proc. Int. Arch. Photogramm. Remote Sens, 39, 567572.

Petrat, L. and Eloff, C. 2014. Integrated use of optical and radar satellite constellations: A new era for remote sensing. Available: http://geospatial-world.net/Paper/Technology/ArticleView. aspx?aid=30793 [Accessed 01 July 2014].

Rexes, M. and Hirt, C. 2014. Comparison of free high resolution digital elevation data sets (ASTER GDEM2, SRTM v2.1/4.1) and validation against accurate heights from the Australian National Gravity Database. Australian Journal of Earth Sciences, 61, 213-226.

Richards, J. A. and Xiuping, J. 2006. Remote sensing digital image analysis: an introduction, Heidelberg, Germany, Springer-Verlag Berlin.

Stampoulidis, L. 2014. G\&H optical fibre amplifiers for next generation satellite communications robust against ionizing radiation. Available: http://goochand-housego.com/press_release/ rad-edfas/ [Accessed 01 July 2014]. 
South African Journal of Geomatics, Vol. 5. No. 3, November 2016

Toutin, T. 2004. Review article: Geometric processing of remote sensing images: models, algorithms and methods. International Journal of Remote Sensing, 25, 1893-1924.

Toutin, T. Sensor orientation and ortho-rectification of high resolution satellite images: Review and application with FERMOSAT-2. Map Middle East 2006 conference proceeding, 2006.

Trimble. February 2011. User Guide: GeoExplorer 6000 Series. Available: http://sendai.hmdc.harvard.edu/cga_website_files/PDF_misc/GPS/GeoExpl6000_UserGde_ ENG.pdf [Accessed 04 July 2014].

Yang, X. and Williams, D. 1997. The effect of DEM data uncertainty on the quality of orthoimage generation. Geographic Information Systems/Land Information Systems (GIS/LIS). Cincinnati, Ohio: American Congress on Surveying and Mapping \& American Society for Photogrammetry and Remote Sensing. 